\title{
PRE-ECLAMPSIA-PREGNANCY INDUCED HYPERTENSION; THREATS AND CONSEQUENCES
}

\author{
Iqra Zulfiqar ${ }^{1 \& 2}$, Naila Mushtaq ${ }^{2 \& 3}$, Sadaf Ahmed ${ }^{2 \& 3}$, Shamoon Noushad ${ }^{2 \& 3}$ \& Saima Khan ${ }^{2 \& 4}$ \\ 1. Baqai Institute of Pharmaceutical Sciences \\ 2. Advance Educational Institute \& Research Centre \\ 3. University of Karachi \\ 4. Aga Khan University \& Hospital \\ Corresponding Author Email: tentative.hermit15@live.com
}

\begin{abstract}
Pre-eclampsia is the elevated blood pressure and excess protein in the urine after 20 weeks of pregnancy in a woman who previously had normal blood pressure, a major cause of preterm birth and an early marker for future cardiovascular and metabolic diseases. The objective of study is to identify the level of awareness regarding pre-eclampsia (pregnancy induced hypertension or gestational hypertension) and its relation with increasing maternal and fetal mortality rate. The questionnaire based survey was conducted including both close \& open ended questions and compared with the retrospective data among 160 respondents, in which our target was to investigate women of varying socioeconomic status $\&$ the duration of our research is almost 20 days. Statistically we found an overall poor awareness of pre-eclampsia with $26 \%$ of women surveyed having heard of it and remaining $74 \%$ were unknown to pre-eclampsia, $39 \%$ faced pre-eclampsia with its severe consequences and fetal mortality rate data showed $42 \%$ deaths stating pre-eclampsia as the major cause of it, in addition to that higher rate of maternal death i.e. 57\% occurs due to pre-eclampsia subsiding other reasons as key reasons of maternal mortality. Hence it is concluded that Pre-eclampsia is a disorder of pregnancy with unknown etiology so awareness level is too low to decrease its incident \& this lack of awareness translates to worse health outcomes proving pre-eclampsia as a major cause of maternal and fetal mortality and its lack of awareness increasing this risk day by day and making it a hidden threat to pregnancy.
\end{abstract}

\section{KEYWORDS}

Pre-eclampsia, pregnancy-induced hypertension, gestational hypertension, maternal mortality, fetal mortality

\section{INTRODUCTION}

Pre-eclampsia is the development of hypertension during pregnancy and the most common and the most potentially serious complication of pregnancy or it can be defined as high blood pressure and excess protein in the urine after 20 weeks of pregnancy in a woman who previously had normal blood pressure. The hypertensive disorders of pregnancy, preeclampsia, and gestational hypertension, which complicate 6 to $8 \%$ of pregnancies (Hopkins, 2000), are leading causes of maternal and fetal morbidity and mortality, and are associated with increased risk of future chronic hypertension (Nisell, 1995). This is diagnosed when there are two or more episodes, more than 4 hours apart, of blood pressure $>140 / 90 \mathrm{mmHg}$ at $\geq 20$ weeks of gestation. 6 Proteinuria is significant if there is $\geq 0.3 \mathrm{~g}$ urinary protein $/ 24$ hours, a spot protein: creatinine ratio $\geq 30$, or $\geq++$ protein on urine dipstick, with no evidence of urinary tract infection. Pre-eclampsia is hypertension and significant proteinuria at $\geq 20$ weeks of gestation with incidence of $2-8 \%$ while gestational hypertension is hypertension at $\geq 20$ weeks of gestation in the absence of significant proteinuria with incidence of $4.2-7.9 \%$ (Green, 2012). Pre-eclampsia is a major cause of maternal and fetal mortality and morbidity.[3] Every day, approximately 800 women die from preventable causes related to pregnancy and childbirth and preeclampsia is one of those causes (Al-Mulhim, 2003). Preeclampsia is a major contributor to maternal mortality worldwide and in Africa and Asia they contribute to 9\% of deaths. (Khan, 2006). Preeclampsia is a major cause of preterm birth and an early marker for future cardiovascular and metabolic diseases, whereas preterm delivery is associated with immediate neonatal morbidity and has been linked to remote cardiovascular and metabolic disease in the newborns (Duley, 2009; Villar, 2003). Precise etiology of pre-eclampsia is still unknown. Factors that appear to have a role include the abnormal placentation, maternal immune response, genetic predisposition, and maternal vascular disease (Harskamp, 2007; North, 1999). If severe, it progresses to fulminant pre-eclampsia with headaches and visual disturbances and Hemolysis elevated liver enzymes and low platelets syndrome (HELLP syndrome)which are life threatening complications resulting in adverse maternal and neonatal outcome. Women with mild pre-eclampsia generally have no symptoms, but when severe have signs and symptoms of renal insufficiency (oligouria, increased serum creatinine) elevated liver enzymes, headaches, visual disturbances, thrombocytopenia, DIC and convulsions (Brown, 2000; Hnat, 2002; Chesley, 1999). More maternal and neonatal complications were encountered in women in whom preeclampsia was severe and pregnancy had to be terminated earlier. $\mathrm{PE}$ is very frequently seen in our population; however local work is very sparse. Few studies have reported maternal and foetal morbidity and mortality associated with this condition.

\section{METHOD}

The questionnaire based survey was conducted including both close $\&$ open ended questions and compared with the retrospective data among 160 respondents, in which our target was to investigate women of varying socio-economic status. In-patient pregnant women in their third trimester were included with age range of 18 years to older. This study was conducted on faculty of different Schools, in-patients of Dept. of Obstetrics and Gynaecology unitFatima Hospital Baqai (Gadap Town) and Dr. Rukhsana Rao 
Maternity Home and Out-patients of Al-Mumtaz Hospital. The duration of our research is almost 20 days i.e., from May 10 to May 30, 2014. Data was analyzed on Excel 2010 in which graphs and percentages were plotted.

\section{RESULTS}

By logistic regression, we experienced result as low overall awareness of pre-eclampsia with $26 \%$ of women surveyed having heard of it and remaining 74\% are unknown to pre-eclampsia. Awareness is lower among un-school respondents, that is $0 \%$ and increase by increasing education as $16 \%$ primary educated, $21 \%$ secondary educated, $19 \%$ higher educated $50 \%$ graduated, $50 \%$ Masters and 100\% MPhil respondents are aware of it. Among 160 respondents $39 \%$ faced pre-eclampsia with its severe consequences and fetal mortality rate data showed $42 \%$ deaths stating preeclampsia as the major cause of it, in addition to that higher rate of maternal death i.e. $57 \%$ occurs due to pre-eclampsia subsiding other reasons like $12 \%$ unskilled staff, $10.40 \%$ anemia, $10 \%$ hemorrhage and $9.6 \%$ several infections as originators of maternal mortality.

\section{Awareness of Pre-eclampsia}

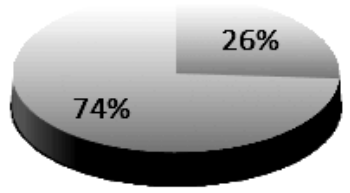

$-\mathrm{YES}=\mathrm{NO}$
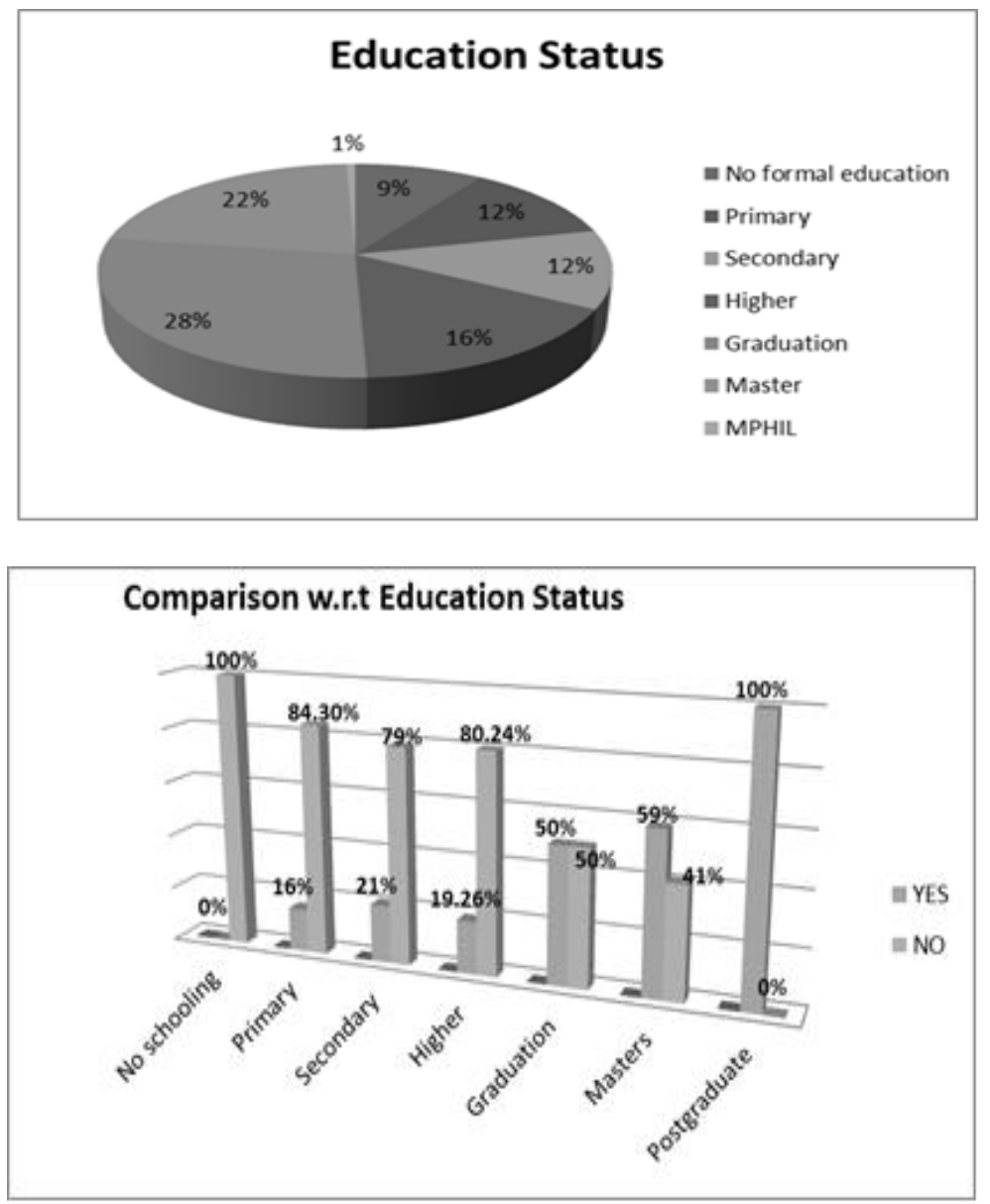

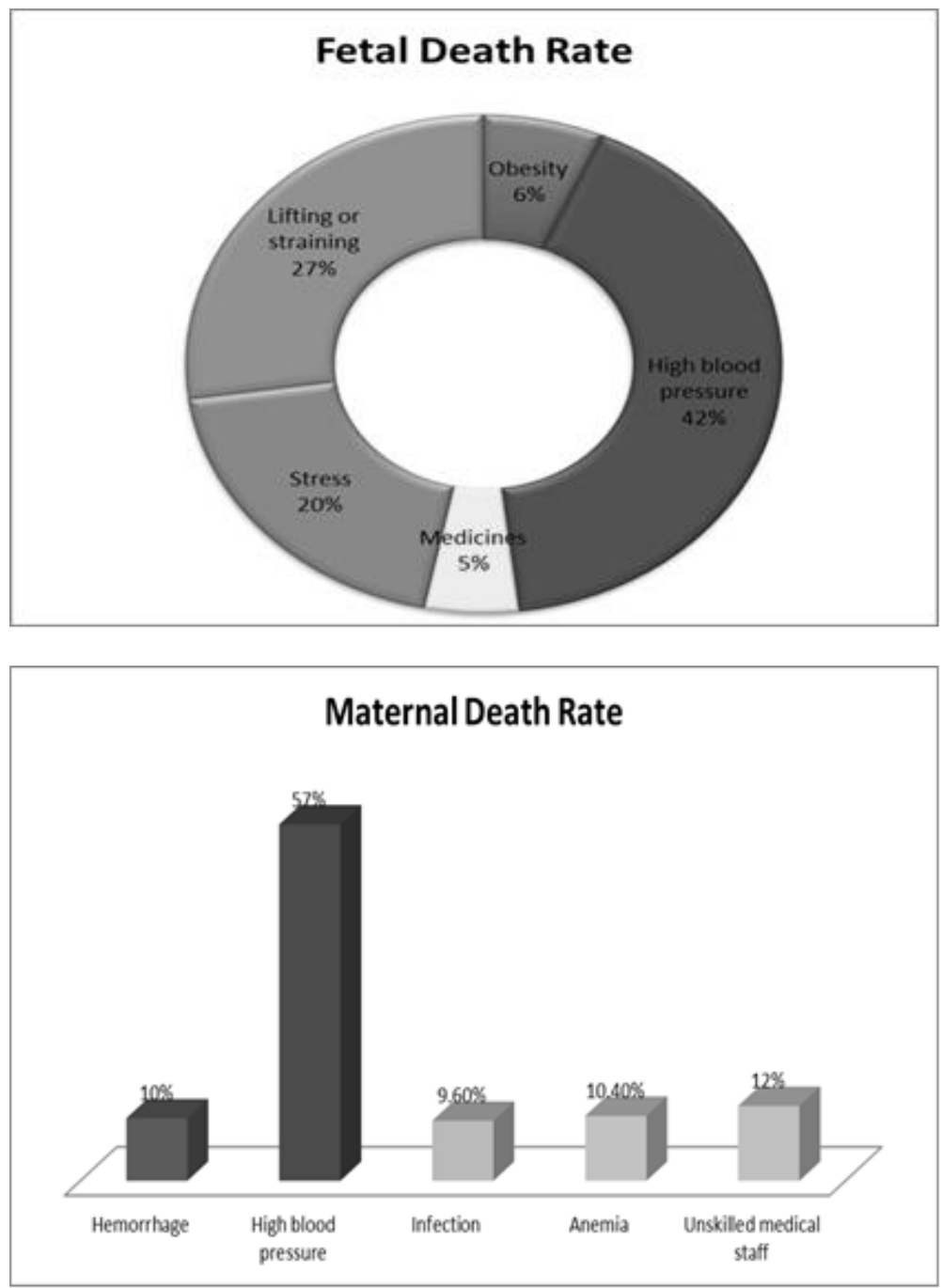

\section{CONCLUSION}

Pre-eclampsia is a disorder of pregnancy with unknown etiology so awareness level is too low to decrease its incident as our research shows that more than half of respondents are not informed about the signs, symptoms and consequences of pre-eclampsia; a lifethreatening condition that complicates one in twelve pregnancies as documented. The awareness level demotes from postgraduates to illiterate individuals respectively, no proper guidance during pregnancy by health care professionals to the mother make her unaware, this lack of awareness translates to worse health outcomes; the incidence of fetal death, high rate maternal death and pre-term births. So in order to decrease the incident of this threatening and alarming condition it should be cured at initial levels with proper guidance, discussions and understanding with health care professionals to overcome and help to improve maternal and neonatal prognosis.

\section{DISCUSSION}

Although previous literatures and updated work regarding preeclampsia awareness, outcomes and etiology based studies shows various reasons causing pre-eclampsia however our primary center is to recognize the center purpose for major fetal conclusions of preeclampsia likewise with awareness level in our general populace in connection to their socioeconomic status.

Pre-eclampsia was associated with higher frequency of maternal morbidity as According to a study from Pakistan, the overall perinatal mortality in hypertensive disorders of pregnancy (including pre-eclampsia) is $13 \%$ ( Ara, 2004), the major causes being prematurity and low birth weight babies who need NICU care. As discussing the results we gathered a very low awareness level we saw in our society i.e. only $24 \%$ respondents are properly known and aware to the consequences, effects and outcomes of pre-eclampsia, the reason majorly indicate the least awareness level as no proper guidance been established by health care individuals or no proper campaigns regarding this issue were witnessed so general public is unaware about the fact of maternal and fetal mortality and morbidity (Jehan, 2004). Relation of education with awareness is not very authentic or confirmed in a fact that no documented proves we have in that context but our data shows increasing awareness level with increased education status. The two major consequences of pre-eclampsia i.e. Maternal and fetal death rate was observed. Frequency of preeclampsia 
responsible for intrauterine death has been reported up to $1 \%$ (Donald, 1995; Moyo, 1995; Odendaal, 1995), but our data rate majorly shows the reason of gestational hypertension as core reason i.e. $42 \%$ which again put a question mark on our living scenarios and awareness level. According to WHO latest report $14 \%$ cases of maternal death are due to pre-eclampsia issues worldwide in comparison to our data which indicates $57 \%$ cases undergo maternal mortality due to least mindfulness regarding elevated blood pressure during pregnancy.

So all cases of PE should be managed according to multidisciplinary approach involving a physician, anesthetist, gynecologist and midwives with proper compliance of mother throughout the period that will decrease the fatality of this alarming condition

\section{REFERENCES}

- Al-Mulhim, A. A., Abu-Heija, A., Al-Jamma, F., \& ElHarith, E. H. (2003). Pre-eclampsia: maternal risk factors and perinatal outcome. Fetal diagnosis and therapy, 18(4), 275280.

- Brown, M. A., Hague, W. M., Higgins, J., Lowe, S., McCowan, L., Oats, J. \& Walters, B. N. J. (2000). The detection, investigation and management of hypertension in pregnancy: full consensus statement. Australian and New Zealand Journal of Obstetrics and Gynaecology, 40(2), 139155.

- Chesley, L. C. (1985). Diagnosis of preeclampsia. Obstetrics \& Gynecology, 65(3), 423-425.

- Donald, I. (1995). Practical obstetric problems (5th ed.) B.I. Publications. H.I.J. Wildschut Sociodemographic factors. W.B Saunders company limited.

- Duley, L. (2009). The global impact of pre-eclampsia and eclampsia. Seminars in Perinatology, 33: 130-137.

- Green, A., Loughna, P., \& Pipkin, F. B. (2012). New-onset hypertension in pregnancy: a review of the long-term maternal effects. The Obstetrician \& Gynaecologist, 14(2), 99-105.

- Harskamp, R. E., \& Zeeman, G. G. (2007). Preeclampsia: at risk for remote cardiovascular disease. The American journal of the medical sciences, 334(4), 291-295.

- Hnat, M. D., Sibai, B. M., Caritis, S., Hauth, J., Lindheimer, M. D., MacPherson, C. \& Dombrowski, M. (2002). Perinatal outcome in women with recurrent preeclampsia compared with women who develop preeclampsia as nulliparas. American journal of obstetrics and gynecology, 186(3), 422426.

- Hopkins, M. P. (2000). Report of the national high blood pressure education program working group on high blood pressure in pregnancy. American journal of obstetrics and gynecology, 183(1), 1-258.

- Jehan, A., Musarrat, J., \& Nadra, S. (2004). Perinatal outcome in pregnancy induced hypertensive mothers. Pak Armed Forces Med J, 54(8), 76-78.

- $\quad$ Khan, K. S., Wojdyla, D., Say, L., Gülmezoglu, A. M., \& Van Look, P. F. (2006). WHO analysis of causes of maternal death: a systematic review. The lancet, 367(9516), 10661074.
- Moyo, S. R., Tswana, S. A., Nyström, L., Bergström, S., Blomberg, J., \& Ljungh, Å. (1995). Intrauterine death and infections during pregnancy. International Journal of Gynecology \& Obstetrics, 51(3), 211-218.

- Nisell, H., Lintu, H., Lunell, N. O., Möllerström, G., \& Pettersson, E. (1995). Blood pressure and renal function seven years after pregnancy complicated by hypertension. BJOG: An International Journal of Obstetrics \& Gynaecology, 102(11), 876-881.

- $\quad$ North, R. A., Taylor, R. S., \& Schellenberg, J. C. (1999). Evaluation of a definition of pre-eclampsia. BJOG: An International Journal of Obstetrics \& Gynaecology, 106(8), 767-773.

- Odendaal HJ, Steyn DW, Norman K, Kirsten GF, Smith J, Theron GB. Improved perinatal mortality rates in 1001 patients with severe pre-eclampsia. S Afr Med J. 1995 Oct; 85(10), 1071-1076.

- Villar, K., Say, L., Gülmezoglu, A. M., Merialdi, M., Lindheimer, M. D., Betran, A. P., \& Piaggio, G. (2003). Eclampsia and pre-eclampsia: a health problem for 2000 years. Pre-eclampsia, 189-207. 
